\title{
Martin Luther King Jr. hoy
}

No habrá paz entre las naciones, Sin paz entre las religiones.

No habrá paz entre las religiones,

Sin diálogo entre las religiones.

No habrá diálogo entre las religiones,

Sin investigación sobre los fundamentos de las religiones.

Hans Küng

Fis

1 día de hoy, 15 de enero de 2015, se cumple el 86 aniversario del nacimiento del pastor bautista y condecorado con el Premio Nobel de la Paz, Martin Luther King Jr., también por extraña coincidencia de la vida es la fecha en que hace 3 años pasó a integrar la comunidad de los fieles ante la presencia del Señor, nuestro hermano, José Miguel Torres h., pastor bautista y teólogo ecuménico, quien brindó desde América Latina, a la lucha por la paz, las bases bíblicas y teológicas para una cultura de paz.

La trascendencia de la obra y pensamiento de Martin Luther King Jr. hacen que sea uno de los Santos que entra al Siglo XXI con un legado permanente vigente, como luz que guía a la humanidad en su lucha por un mundo donde como dice Salmos 84 "La Justicia y la paz se besan".

Después de la abolición de la esclavitud (de los negros) por Lincoln, la lucha y conquista de los derechos civiles de los negros conducidos por Martin Luther King Jr. constituye el logro histórico más importante de esta población que es parte importante de nuestra rica identidad cultural americana.

Sin embargo, llama la atención que un lema de la campaña presidencial que llevó al primer negro a la presidencia de los Estados Unidos, haya sido la reconciliación interna de esta nación y su reconciliación con el mundo.
Los últimos acontecimientos raciales en ese país evidencian que las heridas de su historia aún no han cicatrizado plenamente, es evidente que la conflictividad, incluso violenta, encuentra sus raíces en un sistema injusto que no ha integrado plenamente a este conglomerado en la vivencia de los Derechos Humanos. De ahí que la reconciliación de la sociedad norteamericana pasa por cambios estructurados a nivel socioeconómico, de la justicia y cultura en esa sociedad.

Pero también debemos ser capaces de reconocer y respaldar gestos sustanciales, históricos de reconciliación de Estados Unidos con América Latina, en este sentido se ubican los Decretos Presidenciales del Presidente Obama relativos al factor migratorio que beneficiarán a millones de migrantes latinoamericanos que hacen su vida y aportan al desarrollo norteamericano y también a la propia América Latina.

De igual manera, cabe relevar la decisión histórica del Presidente Obama de restablecer las relaciones diplomáticas con la hermana República de Cuba; este no solo ha sido un acto de justicia en torno a una causa que goza del respaldo mundial, latinoamericano y de la propia sociedad norteamericana; aunque no se puede soslayar que estas decisiones presidenciales se enfrentan a la ultraderecha norteamericana que actualmente hegemoniza al Partido Republicano. Con ello no solo se retoma el derecho y la legalidad internacional, sino que también permite a Cuba iniciar reformas necesarias 
en su sistema económico y político para el bien de esa población.

Inauguramos este nuevo año con signos positivos en América Latina y sus relaciones económicas y políticas con el mundo, pero en una escena internacional marcada por la violencia, la intolerancia y la guerra.

América Latina como comunidad de Estados se ha declarado como Zona de Paz que renuncia al recurso de las armas para dirimir los conflictos entre nuestros países. Este es un paso histórico hacia una Cultura de Paz, como establece la Declaración de la Habana del CELAC de enero 2014.

La conflictividad violenta mundial actual está marcada por la codicia sobre los recursos naturales del planeta, la intolerancia cultural y religiosa, y los proyectos de reconfiguración geoestratégica, en particular en el
medio oriente. Desde el punto de vista de la cultura medio oriente. Desde el punto de vista de la cultura dejar pasar, no con la injusticia y todo aquello que atente contra la dignidad humana. La tolerancia reconoce y estimula la riqueza que representa la diversidad. Los Derechos Humanos como el derecho a la libertad de expresión, uno de los derechos fundamentales por ser inmanentes al ser humano, también conllevan deberes de reconocimiento a los derechos e identidades del Otro. La libertad absoluta no existe cuando vulnera el derecho del Otro, por ello Benito Juárez, decía:

"El respeto al derecho ajeno es la paz".

Sin embargo, una acción que escoge el humor y la sátira en torno a símbolos que le son sagrados a otras culturas y religiones, no puede ser enfrentada con la violencia demencial, sino desde el terreno de las ideas y el conocimiento.

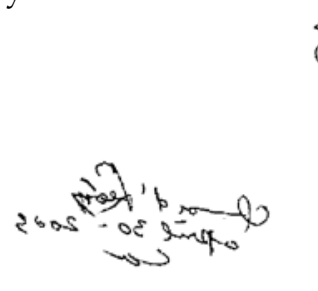

3 isjo

isjis ijs:

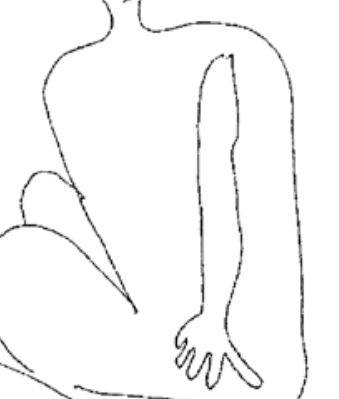

Compartimos la afirmación del Movimiento Internacional de Reconciliación (MIR), en el sentido de que "no hay violencia en Dios, que Dios llama a todos al rechazo radical de la violencia y ninguna violencia puede justificarse, sobre todo aquella cometida en el nombre de Dios". También queremos reafirmar nuestro rechazo a toda forma de racismo y nuestro compromiso de luchar firmemente contra el antisemitismo y la islamofobia.

El diálogo interreligioso, en particular de las grandes religiones monoteístas y el diálogo intrarreligioso, como ha dicho el Profesor Federico Mayor, que identifique, proyecte y promueva sus grandes coincidencias pacificadoras de sus principios, valores y mensajes; la educación para la paz que forma para conocer, a prender y convivir con el otro, pensar en una nueva reconfiguración como lo plantea el filósofo Morín, "que supere las divisiones artificiales heredadas de la dominación colonial y que tome en cuenta los factores étnicos, culturales y religiosos frente al proyecto del gran califato" y las políticas neocoloniales de las potencias; la reactivación y fortalecimiento del Grupo de Alto Nivel para la Alianza de Civilizaciones copresidido por Federico Mayor Zaragoza, creado por las Naciones Unidas (vías pacíficas), la intervención misma de este organismo invocando el capítulo 7 de esta

Carta, están planteados como respuesta a este aspecto de la crisis del mundo actual y encuentran plena vigencia en el pensamiento de justicia, paz y reconciliación de Martin Luther King.

Denis Torres Pérez Director Instituto "Martin Luther King " Universidad Politécnica de Nicaragua UPOLI Managua, 15 de enero de 2015

Autor: Omar d’ León. 